\title{
Impact of European Society of Cardiology and European Association for Cardiothoracic Surgery Guidelines on Myocardial Revascularization on the activity of percutaneous coronary intervention and coronary artery bypass graft surgery for stable coronary artery disease
}

\author{
Martin T. Yates, MRCS, Gopal K. R. Soppa, MRCS, Oswaldo Valencia, MD, Sion Jones, MRCS, \\ Sami Firoozi, FRCP, and Marjan Jahangiri, FRCS(CTh)
}

Objective: Joint guidelines on myocardial revascularization were published by the European Society of Cardi-
ology and European Association for Cardiothoracic Surgery: Patients with left main stem, proximal left anterior
descending, or 3-vessel disease should be discussed with a surgeon before revascularization, and ad hoc percu-
taneous coronary intervention has no elective indication in these categories. We assess the impact of the guide-
lines on referral patterns to a cardiac surgery service at a large-volume cardiac center in the United Kingdom.

Methods: Joint guidelines were published in August 2010. All patients with severe disease undergoing percutaneous coronary intervention at one institution were identified 6 months before (January to June 2010) and 6 months after (January to June 2011) their introduction. Decision-making and surgical referral were determined from minutes of multidisciplinary meeting.

Results: A total of 197 patients underwent elective percutaneous coronary intervention pre-guidelines, of whom 62 had severe disease. Only 6 patients $(9 \%)$ were discussed at a multidisciplinary meeting before intervention. After introduction of the guidelines, elective percutaneous coronary interventions were performed in 164 patients, of whom 42 had surgical disease. Only 8 patients $(17 \%)$ were discussed at a multidisciplinary meeting before intervention $(P=$ not significant). Follow-up was a median of 480 (380-514) days for the pre-guideline group and 104 (31-183) days for the post-guideline group. Ad hoc percutaneous coronary intervention in surgical disease occurred in 8 patients (14\%) pre-guidelines and was unchanged for 9 patients $(26 \%)$ post-guidelines ( $P=$ not significant).

Conclusions: Despite recommendation by both cardiology and cardiac surgical bodies and widespread publicity, a significant number of patients in this single-center study are not receiving optimal treatment recommended by these guidelines. (J Thorac Cardiovasc Surg 2014;147:606-10)

Earn CME credits at

http://cme.ctsnetjournals.org

Coronary revascularization improves both symptoms and survival in patients with significant coronary artery disease. ${ }^{1-3}$ This can be achieved by coronary artery bypass grafting $(\mathrm{CABG})$ or percutaneous coronary intervention (PCI). The safety and efficacy of both procedures have been well established, but there is great variability in their use in clinical practice. ${ }^{4}$ With this in mind, a joint consensus

From the Departments of Cardiology and Cardiac Surgery, St George's Hospital, London, United Kingdom.

Disclosures: Authors have nothing to disclose with regard to commercial support.

Received for publication Oct 17, 2012; revisions received Dec 20, 2012; accepted for publication Jan 14, 2013; available ahead of print Feb 11, 2013.

Address for reprints: Marjan Jahangiri, FRCS(CTh), Department of Cardiac Surgery,

St George's Hospital, Blackshaw Rd, London SW17 0QT, United Kingdom

(E-mail: marjan.jahangiri@ stgeorges.nhs.uk).

0022-5223/\$36.00

Copyright (C) 2014 by The American Association for Thoracic Surgery

http://dx.doi.org/10.1016/j.jtcvs.2013.01.026 between surgeons and cardiologists was required to guide practice on the basis of current best evidence. A group composed of cardiac surgeons and interventional and noninterventional cardiologists has recently produced joint guidelines for the European Society of Cardiology (ESC) and European Association for Cardiothoracic Surgery (EACTS). ${ }^{5}$ These guidelines provide a framework to assist in decisionmaking for patients requiring elective coronary revascularization.

The ESC/EACTS Guidelines state that in patients with stable coronary artery disease, those with 1- or 2-vessel disease, not involving the proximal left anterior descending (LAD) artery, should be offered PCI. More extensive disease involving the left main stem (LMS) or proximal LAD, or those with 3 -vessel disease should be considered for CABG in the first instance. Specific mention is made of high-risk groups, including patients with chronic kidney disease, left ventricular failure, and diabetes, in whom surgery is the preferred option.

All patients with coronary artery disease who are being considered for revascularization will undergo a diagnostic angiogram. Intervention performed during this procedure 


\section{Abbreviations and Acronyms \\ $\mathrm{CABG}=$ coronary artery bypass grafting \\ EACTS $=$ European Association for Cardiothoracic Surgery \\ ESC = European Society of Cardiology \\ LAD $=$ left anterior descending \\ LMS = left main stem \\ PCI = percutaneous coronary intervention \\ $\mathrm{RCA}=$ right coronary artery}

is known as ad hoc PCI. In a large series of 38,431 patients receiving ad hoc PCI, up to $30 \%$ were potentially candidates for $\mathrm{CABG}^{6}{ }^{6}$ The guidelines make a specific recommendation that stable patients should have intervention deferred. This allows discussion with a surgeon and provides time for the patient to understand the options available to them. ${ }^{5}$

The ESC/EACTS Guidelines place particular emphasis on a multidisciplinary approach and suggest that a Heart Team containing both cardiologists and surgeons discuss complex patients before intervention. Furthermore, patients being treated against the guidelines, for whatever reason, should be discussed with the Heart Team before intervention. ${ }^{5}$ The aim of this study is to evaluate the effect of the publication of the ESC/EACTS Guidelines on revascularization practice at a cardiothoracic unit in the United Kingdom.

\section{PATIENTS AND METHODS \\ Patient Population}

The study was carried out at St George's Hospital, London, United Kingdom, a teaching hospital with a tertiary Cardiology and Cardiothoracic Surgery Unit representing a significant proportion of the coronary revascularization workload of NHS London.

\section{Timing of Study}

The ESC/EACTS Guidelines on Coronary Revascularization were published in August 2010 and presented in detail to the multidisciplinary team at our hospital. To study the impact of the guidelines, patients undergoing coronary revascularization from January to June 2011 were studied. Patients who had undergone revascularization from January to June 2010 were used as control population. This allowed time for the guidelines to be incorporated into practice and prevent seasonal bias.

\section{Database}

All patients undergoing revascularization at St George's Hospital during the study period were identified. Surgical patients were identified from the Central Cardiac Audit Database, and those undergoing PCI were identified from The British Cardiovascular Intervention Society database. These data are collected during every PCI procedure, with a final set of data entered after patient discharge. All patients having undergone PCI during the study periods were identified. Those undergoing previous cardiac surgery were excluded.

A database of all patients discussed at the multidisciplinary meeting at St George's Hospital during the stated time periods was compiled from contemporaneous minutes recorded at each meeting. Minutes are written by a dedicated member of staff at each meeting recording the diagnosis, management plan, and reasons for deviation from expected practice. The minutes are then circulated to all physicians and surgeons who attend the meeting for approval before finalization.

\section{Definitions}

Elective procedures were those carried out on stable patients usually as a day case procedure. Urgent procedures were those carried out as an inpatient, usually for non-ST-segment elevation myocardial infarction or unstable angina. Emergency procedures were those carried out before the start of the next working day, usually primary PCI due to ST-segment elevation myocardial infarction.

Coronary artery stenosis was defined as narrowing of $50 \%$ or greater of vessel diameter at angiography. Three-vessel disease was defined as stenosis of the right coronary artery (RCA), LAD, and circumflex artery.

\section{Outcomes}

The notes or electronic patient records were reviewed for all patients and correlated with the multidisciplinary meeting database to determine which patients had been discussed by the multidisciplinary team. Secondary outcomes investigated were vessels intervened on, subsequent revascularization, and in-hospital mortality.

Data are presented as a mean \pm standard deviation. Categoric data were tabulated for chi-square and Fisher exact test. To compare mean differences, the normality test (Shapiro-Wilk) (age) was performed for continuous data and Student $t$ tests were performed for independent samples.

\section{RESULTS}

\section{Revascularization Activity}

From January to June 2010, before publication of the guidelines, there were a total of 504 PCIs performed, excluding those patients who had undergone previous cardiac surgery. Of these, 197 were elective, 147 were urgent, and 160 were emergency. There were 264 isolated CABGs performed during the same time period. From January to June 2011, after publication of the guidelines, 498 PCIs were performed, 164 elective, 138 urgent, and 196 emergency. There were 260 isolated CABGs performed during the same period. There was no significant change in activity of elective PCI $(P=.34)$ or CABG $(P=.4)$ after publication of the guidelines.

\section{Referral Patterns to Cardiac Surgery}

In 2010, 67 patients (34\%) undergoing elective PCI had disease potentially suitable for CABG. Only $6(9 \%)$ of these were discussed with a cardiac surgeon before intervention. This compares with $48(29 \%)$ of all elective PCIs in 2011, of which $8(17 \%)$ were discussed with a surgeon (Figure 1). A small number $(2010 \mathrm{n}=5,2011 \mathrm{n}=6)$ of these PCIs were for in-stent restenosis and excluded from further analysis. The demographics of both groups were similar. There was no difference in the proportion of procedures carried out since the introduction of the guidelines (34\% vs $29 \% ; P=.26$ ).

During both time periods, the demographics of the groups not discussed with a surgeon were similar. The average age was $65 \pm 6$ years in 2010 and $67 \pm 8$ years in 2011 $(P=.03)$. A significant number of patients had diabetes in 


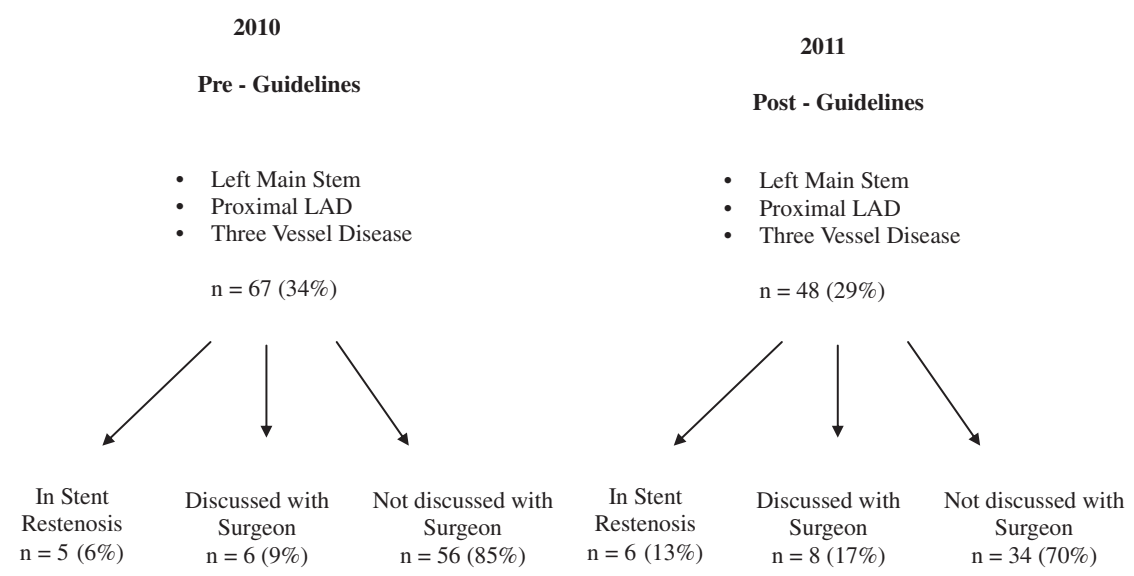

FIGURE 1. Patients with severe coronary artery disease who underwent elective PCI. $L A D$, Left anterior descending.

both groups ( 15 vs $5 ; P=.18)$. Other risk factors included hypertension (40 vs $19 ; P=.13$ ) and smoking (30 vs 14 ; $P=.38$ ) (Table 1).

Of those who were not discussed with a surgeon in 2010, 40 patients $(71 \%)$ had proximal LAD disease, 14 patients $(25 \%)$ had 3-vessel disease, and 2 patients $(4 \%)$ had LMS stenosis. In 2011, 22 patients $(65 \%)$ had disease in proximal LAD, 8 patients $(24 \%)$ had 3 -vessel disease, and 4 patients $(11 \%)$ has LMS disease. Table 2 shows the completeness of revascularization for each of these categories of disease.

Of the 2010 cohort with 3-vessel disease, 10 patients (71\%) had a single-vessel PCI and the remaining patients had 2 vessels treated. Of these, 4 patients $(29 \%)$ underwent further PCI after a mean of 18 weeks (range, 0-30 weeks). There was 1 death $(7 \%)$, and mean follow-up was 480 days (range, 380-514 days). In 2011, 6 (67\%) of those with 3-vessel disease had single-vessel intervention, and the other had 2 vessels treated. During follow-up, 2 patients $(22 \%)$ underwent further PCI after 10 weeks (range, 6-14

TABLE 1. Demographics of patients undergoing elective percutaneous coronary intervention for severe coronary artery disease who were not discussed with a surgeon before intervention

\begin{tabular}{lccc}
\hline \multicolumn{1}{c}{ Demographic } & $\mathbf{2 0 1 0}(\mathbf{n}=\mathbf{5 6})$ & $\mathbf{2 0 1 1}(\mathbf{n}=\mathbf{3 4})$ & $\boldsymbol{P}$ value \\
\hline Male/female & $40 / 16$ & $31 / 3$ & .03 \\
Age (y) & $65 \pm 11$ & $67 \pm 11$ & .26 \\
Previous MI & 15 & 10 & .59 \\
Previous PCI & 16 & 9 & .83 \\
Diabetes & 15 & 5 & .18 \\
Hypertension & 40 & 19 & .13 \\
Cerebrovascular accident & 1 & 0 & 1 \\
Renal failure & 0 & 0 & N/A \\
Smoking history & 30 & 14 & .38 \\
Good LV function & 56 & 30 & .32 \\
\hline$M I$, Myocardial infarction; $P C I$, & percutaneous coronary intervention; $L V$, left \\
ventricle; $N / A$, not available. & & &
\end{tabular}

weeks). There were no deaths. Mean follow-up was 104 days (range, 31-183 days).

\section{Ad Hoc Percutaneous Coronary Intervention Activity}

A significant proportion of elective PCIs with disease potentially suitable for CABG were intervened on in an ad hoc fashion. There were $8(14 \%)$ in 2010 and $9(26 \%)$ in 2011. In 2010,5 patients $(63 \%)$ had proximal LAD disease, and the remainder had 3-vessel disease. In 2011, 6 patients $(67 \%)$ had proximal LAD disease, and the remainder had 3 -vessel disease.

In the 2010 group, of those with proximal LAD involved, all 5 had PCI to LAD. Two patients had disease in a second vessel that was not revascularized. Those with 3-vessel disease had PCI to proximal LAD only, proximal LAD + RCA, and circumflex + RCA with staged PCI to proximal LAD (Table 3).

TABLE 2. Completeness of revascularization in patients with severe coronary artery disease not discussed with a surgeon

\begin{tabular}{lcc}
\hline \multicolumn{1}{c}{ Disease pattern } & $\mathbf{2 0 1 0}(\mathbf{n}=\mathbf{5 6})$ & $\mathbf{2 0 1 1}(\mathbf{n}=\mathbf{3 4})$ \\
\hline Isolated proximal LAD disease & & \\
$\quad$ Complete revascularization & 21 & 13 \\
$\quad$ Incomplete revascularization & 0 & 0 \\
Proximal LAD disease + other stenosis & & \\
$\quad$ Complete revascularization & 8 & 4 \\
$\quad$ Complete revascularization - staged & 1 & 0 \\
$\quad$ Incomplete revascularization & 10 & 5 \\
LMS disease & & \\
Complete revascularization & 0 & 0 \\
$\quad$ Incomplete revascularization & 2 & 4 \\
3-vessel disease & & \\
$\quad$ Complete revascularization & 0 & 1 \\
Complete revascularization - staged & 4 & 2 \\
$\quad$ Incomplete revascularization & 10 & 5 \\
\hline LAD, Left anterior descending; $L M S$, left main stem. &
\end{tabular}


TABLE 3. Completeness of revascularization of patients who underwent ad hoc percutaneous coronary intervention for stable coronary artery disease

\begin{tabular}{lll}
\hline \multicolumn{1}{c}{ Disease pattern } & $\mathbf{2 0 1 0}(\mathbf{n}=\mathbf{8})$ & $\mathbf{2 0 1 1}(\mathbf{n}=\mathbf{9})$ \\
\hline Proximal LAD & 3 & 4 \\
$\quad$ Complete revascularization & 0 & 0 \\
$\quad$ Incomplete revascularization & & \\
Proximal LAD disease + other stenosis & 0 & 1 \\
$\quad$ Complete revascularization & 0 & 0 \\
Complete revascularization - staged & 2 & 1 \\
$\quad$ Incomplete revascularization & & \\
3-vessel disease & 0 & 0 \\
$\quad$ Complete revascularization & 1 & 0 \\
Complete revascularization - staged & 2 & 3 \\
$\quad$ Incomplete revascularization & &
\end{tabular}

$L A D$, Left anterior descending.

In the 2011 group, of those with proximal LAD involvement, 4 had the LAD stented, 1 had the LAD + obtuse marginal, and 1 had the RCA with staged PCI to LAD. Of those with 3 -vessel disease, 1 had the LAD stented, 1 had the circumflex stented, and 1 had both stented (Table 3). The demographics of both groups were statistically similar. There was no difference in the incidence of ad hoc PCI between the 2 groups ( $14 \%$ vs $26 \% ; P=$ not significant).

\section{DISCUSSION}

This study has clearly demonstrated that despite the recent publication of guidelines supported by both the ESC and EACTS, many elective patients requiring coronary revascularization are not receiving management based on these recommendations.

Before the publication of the ESC/EACTS Guidelines in 2010, there had been no recent joint guidance on elective myocardial revascularization produced by medical and surgical societies. The ESC Guidelines were published in $2005,{ }^{7}$ the same year as the American College of Cardiology/American Heart Association Guidelines were produced. ${ }^{8}$ It is notable that of the combined 70 authors of these guidelines, only 1 was a surgeon. ${ }^{9}$ Furthermore, the most recent guidance on CABG was published by the American Heart Association in 2004. ${ }^{10}$ This has led to a disparity in consensus between surgeons and cardiologists, resulting in a variation in the management of patients requiring elective revascularization. A review of the 16,142 patients in the New York State Registry with coronary artery disease showed that of those with indications for surgery according to American College of Cardiology/American Heart Association Guidelines, only 53\% were recommended for surgery. ${ }^{4}$ The results of our study looking at the ESC/EACTS Guidelines are similar.

The SYNTAX trial was a prospective randomized controlled trial of PCI versus CABG in 1800 patients with LMS and triple-vessel coronary artery disease. The trial stratified patients by the angiographic complexity of their disease using the SYNTAX score. At 1 year, the groups had similar overall death rates, but cardiac death was higher in the PCI group compared with CABG $(3.7 \%$ vs $2.1 \%$, $P=.05)$. Furthermore, revascularization rates were significantly higher in the PCI group $(13.5 \%$ vs $5.9 \%, P<.001)$. However, CABG had a higher stroke rate than PCI $(2.2 \%$ vs $0.6 \%, P=.003)$. At St George's Hospital during the same period, stroke rates were $1.86 \%$ versus $0.3 \%$ for CABG and PCI, respectively. These 1-year outcomes of SYNTAX, although not included in the ESC/EACTS Guidelines, became available when they were published, giving further support to the use of surgery in 3-vessel and LMS disease. ${ }^{11}$ The accompanying editorial states the importance of the heart team, which is reinforced by the guidelines. ${ }^{12}$

The benefit of CABG in comparison with PCI is becoming increasingly evident. ${ }^{13}$ The 3 -year outcomes of the SYNTAX trial, published after our study, found that patients with 3-vessel disease undergoing CABG have significant reduction in all-cause mortality $(9.5 \%$ vs $5.7 \%$, $P=.02)$ and repeat revascularization $(10 \%$ vs $19.4 \%$, $P<.001)$. Of note, stroke rates become similar in both groups ( $3.2 \%$ vs $2 \%, P=.07)$.

However, the trial has shown similar outcomes for those with LMS disease and low/intermediate SYNTAX score and those with a low SYNTAX score and 3-vessel disease. ${ }^{14}$ Of note, the ESC/EACTS Guidelines do not differentiate patients by SYNTAX score.

Analysis of high-risk groups included in the SYNTAX trial has shown significantly higher mortality in diabetic patients undergoing PCI compared with nondiabetic persons $(13.6 \%$ vs $6.9 \% ; P=.002)$. Mortality after CABG was similar in these 2 groups $(8.7 \%$ vs $6.1 \% ; P=.153)$. Major adverse cardiovascular and cerebrovascular events were higher in diabetic patients undergoing PCI compared with CABG $(37 \%$ vs $22.9 \% ; P=.001)$, driven mainly by repeat revascularization rate $(20 \%$ vs $12.9 \% ; P<.001) .{ }^{15}$

More recently, the outcomes of the FREEDOM trial, a trial of 1900 patients with diabetes and multivessel coronary artery disease randomized to receive PCI or CABG, has been published. The primary end point of death, myocardial infarction, and stroke occurred more often in the PCI group $(26.6 \%$ vs $18.7 \%, P=.005)$. At 5 years, those undergoing PCI had significantly higher mortality than the CABG group $(16.3 \%$ vs $10.9 \%, P=.049) .{ }^{16}$ This again supports surgery in high-risk groups with severe coronary artery disease.

Ad hoc PCI is common practice in the United States, but there are little data on its prevalence in Europe. In a study using the New York Registry, it has been shown that approximately $30 \%$ of patients undergoing ad hoc PCI were potentially suitable for surgical revascularization. However, the study does not report on outcomes in this specific group. ${ }^{6}$ Potential benefits include shorter hospital stay, reduced procedural complications, and lower contrast dose. The 
disadvantage is the absence of multidisciplinary team discussion and therefore inability to fully inform patients regarding their options. ${ }^{17}$ The fact that ad hoc PCI continues against the ESC/EACTS Guidelines is of concern.

As the range of options for revascularization in patients with coronary artery disease expands, it is becoming increasingly important for surgeons and cardiologists to work together to provide the best possible service for each individual patient. This involves having up-to-date knowledge of best evidence, discussing patients at a multidisciplinary team meeting, and providing patients with information required to decide on their preferred treatment. Clinical governance already dictates that all of these discussions should be clearly documented, and scrutiny of this will undoubtedly increase in the future.

There are a variety of reasons why current practice does not seem to have been influenced by the introduction of the ESC/EACTS Guidelines. The changes required would significantly alter the incidence of PCI and CABG. Furthermore, many cardiologists do not believe the Joint European Guidelines reflect current best evidence, especially with the publication of the SYNTAX trial subsequent to these guidelines. This study has shown that current practice does not fully use the Heart Team, a practice that would need to change to fully incorporate the guidelines.

\section{Study Limitations}

Although this is a single-center study, it was carried out at a large academic cardiothoracic center representing a significant proportion of the revascularization practice across London.

\section{CONCLUSIONS}

The recent publication of the joint consensus on elective revascularization has provided a framework to assist decision-making in patients with coronary artery disease. Currently, there is a significant number of patients not receiving the optimal treatment recommended. Further work is required to increase multidisciplinary team working and awareness of current guidelines.

\section{References}

1. Yusuf S, Zucker D, Peduzzi P, Fisher LD, Takaro T, Kennedy JW, et al. Effect of coronary artery bypass graft surgery on survival: overview of 10-year results from randomized trials by the Coronary Artery Bypass Graft Surgery Trialists Collaboration. Lancet. 1994;34:563-70.

2. Hannan EL, Racz MJ, Walford G, Jones RH, Ryan TJ, Bennett E, et al. Long term effects of coronary artery bypass grafting versus stent implantation. $N$ Engl J Med. 2005;352:2174-83.

3. Hannan EL, Wu C, Walford G, Culliford AT, Gold JP, Smith CR, et al. Drug eluting stents vs coronary artery bypass grafting in multivessel coronary disease. N Engl J Med. 2008;358:331-41.

4. Hannan EL, Racz MJ, Gold J, Cozzens K, Stamato NJ, Powell T, et al. Adherence of catheterisation laboratory cardiologists to American College of Cardiology/ American Heart Association guidelines of percutaneous coronary interventions and coronary artery bypass graft surgery: what happens in actual practice? Circulation. 2010;121:267-75.

5. Wijns W, Kolh P, Danchin N, Di Mario C, Folk V, Folliguet T, et al. ESC/EACTS guidelines on myocardial revascularization. Eur Heart J. 2010;31:2501-55.

6. Hannan EL, Samadashvili Z, Walford G, Holmes DR, Jacobs A, Sharma S, et al. Predictors and outcomes of ad hoc versus non ad hoc percutaneous coronary interventions. JACC Cardiovasc Int. 2009;2:350-6.

7. Silber S, Albertson P, Aviles FF, Camici PJ, Colombo A, Hamm C, et al. Guidelines for percutaneous coronary interventions. Eur Heart J. 2005;26:804-47.

8. Smith SC, Feldman TE, Hirshfeld JW Jr, Jacobs AK, Kern MJ, King SB III. ACC/AHA/SCAI 2005 guideline update for percutaneous coronary intervention. Circulation. 2006;113:156-75.

9. Taggart DP. Thomas B Ferguson Lecture. Coronary artery bypass grafting is still the best treatment for multivessel and left main stem disease, but patients need to know. Ann Thorac Surg. 2006;82:1966-75.

10. ACC/AHA 2004 guideline update for coronary artery bypass graft surgery: a report of the American College of Cardiology/American Heart Association Task Force on Practice Guidelines. Circulation. 2004;110:1168-76.

11. Serruys PW, Morice M, Kappetein AP, Colombo A, Holmes DR, Mack MJ. Percutaneous coronary intervention versus coronary artery bypass grafting for severe coronary artery disease. N Engl J Med. 2009;360:961-72.

12. Lange RA, Hills LD. Coronary revascularization in context. N Engl J Med. 2009; 360:1024-6.

13. Taggart DP. Lessons learned from the SYNTAX trial for multi vessel and left main stem coronary artery disease. Curr Opin Cardiol. 2011;26:502-7.

14. Kappetein AP, Feldman TE, Mack MJ, Morice M, Holmes DR, Stahle E, et al. Comparison of coronary bypass surgery with drug electing stenting for the treatment of left main and/or three-vessel disease: 3 year follow-up of the SYNTAX trial. Eur Heart J. 2011;32:2125-34.

15. Mack MJ, Banning AP, Serryus PW, Morice MC, Taeymans Y, Van Nooten G, et al. Bypass versus drug eluting stents at three years in SYNTAX patients with diabetes mellitus and metabolic syndrome. Ann Thorac Surg. 2011;92: 2140-6

16. Farkouh ME, Domanski M, Sleeper LA, Siami FS, Dangas G, Mack M, et al. Strategies for multivessel revascularization in patients with diabetes. $N$ Engl J Med. 2012;367:2375-84.

17. Chandrasekharan DP, Taggart DP. Informed consent for interventions in stable coronary artery disease: problems, etiologies and solutions. Eur J Cardiothorac Surg. 2011;39:912-7. 